\title{
ИНТЕРПРЕТАЦИЯ МЕТОДИЧЕСКОГО СОМНЕНИЯ \\ Э. ГУССЕРЛЕМ И Ж.-П. САРТРОМ: ТРАНСЦЕНДЕНТАЛЬНОЕ И ТРАНСЦЕНДЕНТНОЕ ЕGО В ТЕОРИИ ИНТЕРСУБЪЕКТИВНОСТИ
}

\section{Т.Н. Бурлаченко}

В концепциях Э.Гуссерля и Ж.-П.Сартра интерпретация радикального сомнения Р. Декарта является переломным пунктом для постановки вопроса о возможности и природе интерсубъективной взаимосвязи между отдельными еgо. Обращение к методу Декарта в обоих случаях совершается в рамках конструирования авторами собственного проекта «эгологии» и предполагает переосмысление картезианского учения об ego cogito в свете постулатов феноменологии.

Э. Гуссерль, подобно Р. Декарту, был движим целью обосновать непротиворечивую теорию познания, которая легла бы в основание всех прочих наук. Истолкование методического сомнения представлено в «Картезианских размышлениях», где Гуссерль опирается на «Размышления о первой философии» Декарта. Применение данного метода связанно с дескрипцией структуры трансцендентального еgо, которое стало предметом феноменологии после ее так называемого «трансцендентального поворота». Главным предметом критики положений, изложенных Гуссерлем в этот период, и камнем преткновения, препятствующим научной строгости феноменологии, оказалась солипсистская установка феноменолога, которую он рискует занять вследствие осуществления феноменологической редукции. В «Картезианских раз- 
мышлениях» Гуссерль презентует стратегию преодоления солипсизма путем обоснования возможности интерсубъективного взаимодействия. Таким образом, опираясь на философию Декарта, он преследует одновременно две цели: переосмыслить радикальное сомнение в рамках трансцендентально-феноменологического метода и обосновать интерсубъективную взаимосвязь между сообществом трансцендентальных ego, понятую как условие конституирования единой и объективно данной картины мира.

Метод Декарта Гуссерль истолковывает как прообраз феноменологической редукции. Соответственно, прямой аналогией картезианского сомнения является єлохи́ - воздержание от суждения о бытии мира вне познающего субъекта. Согласно Гуссерлю, принцип єло позволяет редуцировать «свое естественное человеческое Я и свою душевную жизнь $[\ldots]$ к своему трансцендентально-феноменологическомy Я» $[1$, c. 77$]$.

Характерно, что для Декарта сомнение служило средством возможного перехода от сферы эмпирического, чувственного опыта к сфере рационально постигаемых идей и аксиом ${ }^{1}$. С точки зрения Гуссерля, позиция Декарта находится в слишком тесной связи, как с теологическими построениями его времени, так и с ориентацией на построение идеальной науки «ordine geometrico», основанием которой является оперирование аксиомами. Первой из таковых аксиом, согласно Декарту, является «Cogito ergo sum». Критикуя его за «трансцендентальный реализм», Гуссерль противопоставляет позиции Декарта собственное учение о трансцендентальном субъективизме, которое не имеет в своей основе никакого объективно значимого знания. Таковым учением является наука о феноменах. Согласно задумке Гуссерля, она ориентирована на неповторимые и единичные данные опыта конкретного индивидуума, которые, в отличии от математического знания, не име-

\footnotetext{
${ }^{1}$ Пример с грудкой воска, приводимый Декартом во Втором размышлении, указывает на рациональный характер познания мыслящей субстанции и рационально постижимой природы вещей, которые познаются как внешние ей: «Мне остается признать, что я, собственно, и не представлял себе, что есть данный воск, но лишь воспринимал его мысленно» [2, с. 26], «Таким образом, то, что я считал воспринятым одними глазами, я на самом деле постигаю исключительно благодаря способности суждения» [там же, с. 27]. См. также его итоговое заключение, высказываемое в Шестом размышлении: «Итак, телесные вещи существуют. Правда, быть может, они существуют не вполне такими, какими воспринимают их мои чувства, поскольку такое чувственное восприятие у многих людей весьма туманно и смутно; однако в них, по крайней мере, содержится все то, что я постигаю ясно и отчетливо, или, иначе говоря, все, взятое в общем и целом, что постигается в предмете чистой математики» [там же, с. 64].
} 
ют универсального и общезначимого характера.

Ego, понятое по аналогии с математической аксиомой, Гуссерль замещает положением о трансцендентальном субъекте. Вместе с тем, он настаивает на адекватности применения картезианского метода для разрешения задач феноменологии. Однако, согласно картезианской позиции, субъект сомнения мог реализовать этот акт ввиду существования абсолютной и несомненной истины, которая, к тому же, не положена познающему уму извне, но сама есть источник существования мыслящего (и сомневающегося) Я. Этим источником в системе Декарта является Бог. Возможность интерсубъективных отношений также имеет свое основание в Боге:

А если в мире и имеются какие-либо тела, какие-либо интеллигенции или иные природы, не имеющие всех совершенств, то существование их должно зависеть от его могущества, так что без него они не могли бы просуществовать и одного мгновения [3, с. 271].

Само собой, принятие подобной установки неприемлемо в рамках научной феноменологии. Воздерживаясь от суждения о существовании воспринимаемых предметов за пределами сознания, Гуссерль отстраняется от любых теологических допущений.

Исследование структур сознания по проведении феноменологической редукции и возможность познания Другого, Гуссерль некритически причисляет к одному и тому же тематическому полю. Однако, в рамках так поставленного вопроса наличествует противоречие между необходимостью удостоверить Я, существующее как агент интерсубъективного взаимодействия, и прежде уже существующим субъективным основанием, обеспечивающим возможность такого взаимодействия - Я, лежащим в ядре трансцендентального сознания.

Собственно, не только Декарт, но и не в меньшей степени И. Кант, является предтечей феноменологии. Обращаясь к картезианской формуле, Кант замечал, что существование не может выступать предикатом мыслящего субъекта, поскольку для мысли о сущестовании остается непроницаемым основание существования мыслящего. Характерно, что акт познания не имеет основания в Боге: констатировать аксиому еще не значит постигнуть характер ее (и собственной) причастности к Богу. Самопознание не распространимо на статус собственного существования и продуктивно только относительно восприятия себя самого как феномена, данного в априорном временном переживании. Субъект синтеза трансцендентальной апперцепции не имеет никакого онтологического преимущества относительно содержания сознания: он 
не есть нечто обуславливающее сознание, но, напротив, сам обусловлен деятельностью актов сознания. Следовательно, не может идти и речи о том, что ему доступен интерсубъективный опыт, предполагающий трансцендирование за собственные пределы.

Продолжая мысль Канта, Гуссерль считает, что развернутое или эмпирическое знание себя самого Я обретает во временном потоке своего сознания. Однако, вместе с тем он полагает, что первично Я отличается от априорных форм сознания, будучи обуславливающим его деятельность центром, а не продуктом (синтеза трансцендентальной апперцепции), что характерно для позиции Канта. Таким образом, времени, имманентному сознанию, предшествует то самое Я, которое сомневается и существует в процессе мысли, как вневременное и есть «трансценденция в пределах имманентности» (цит. по: [4, с. 183]).

Предпринимая в «Картезианских размышлениях» попытку обосновать интерсубъективную взаимосвязь между еgо, Гуссерль остается в рамках проблемы, генезис которой восходит к «Критике чистого разума» Канта. Согласно Гуссерлю, акт конституирования мира различными ego осуществляется в едином времени:

мы видим, что временное сообщество монад ${ }^{2}$, конститутивно соотнесенных друг с другом, нерушимо, поскольку оно существенным образом связано с конституцией мира и временем этого мира [1, с. 241].

Так, субъекты взаимосвязаны друг с другом не эгологически, но в единстве временной канвы, пронизывающей их трансцендентальный познавательный аппарат. Именно общность феноменальных данных оказывается достаточным основанием для опровержения солипсизма. Но из этого следует, что субъект сомнения и источник солипсистской позиции, не имеет непосредственной связи с Другим: ego с ego. Мыслящее Я лишь совершает акт аппрезентации, т. е. умозаключения, что Другой существует по аналогии с его собственным телом и сознанием. Следовательно, отношение с Другим устанавливается в средоточии интенционально воспринимаемого мира сущих предметов.

\footnotetext{
${ }^{2}$ Темой, требующей самостоятельного рассмотрения, является рецепция учения Г. Лейбница в гуссерлианском проекте феноменологии в целом и теории интерсубъективности, в частности. Ограничимся указанием на то, что, согласно Гуссерлю, в рамках монадологии осуществлен переход к сознанию в полноте его интенционально воспринятых содержаний, который, хотя и был потенциально возможным, остался неосуществленным в учении Декарта. См. подробнее: [4], [5], а также: $A p$ теменко H.A. Монадология как феноменология vs феноменология как монадология // Известия Уральского Федерального университета. Серия 3. Общественные науки. - 2014.- Т. 128. - № 2. - С. 148-168.
} 
Характерно, что если в «Критике чистого разума» речь идет о трансцендентализме априорных форм познающего субъекта, то в «Критике практического разума» Кант пишет о субъекте «трансцендентальной свободы». Он делает различие между двумя Я и указывает на приоритет самоидентификации $Я$, как существа морального, перед установкой Я познающего (мысленно либо сенсуально). С одной стороны, он, тем самым, обосновывает гносеологию в качестве основы научного познания, с другой - этику, являющуюся основанием для исполняющего долг свободного Я. В ней берут свое начало конкретные отношения с другими людьми, а также постижение индивидуальной взаимосвязи с Богом.

Разработав концепцию, базисом которой является кантианский вариант трансцендентальной философии, Гуссерль возвращается в «Картезианских размышлениях» к методическому сомнению в контексте проблем, поставленных Кантом в «Критике чистого разума»проблем, которых попросту не существовало для Картезия. Последний, утверждая, что совершенство Бога есть условие его существования (ибо существование - одно из его совершенств) и, одновременно, возможности интеллектуального познания благости его природы и истинности его творения, не мог провести линию раздела между Я познающим и Я моральным. Подобно тому, как истина математической аксиомы необходимо предшествует действительности эмпирического опыта, истина самоудостоверения гарантирует моральную природу Я.

Таким образом, различие, проведенное Кантом между Я познающим и Я долженствующим (акт рефлексии которого сопряжен с осознанием собственной свободы), не учтено Гуссерлем. Обращение к методологии Декарта происходит без учета того, что проблема дескрипции конституирования действительности в сознании не равноценна проблеме обоснования интерсубъективной связи субъектов. Следствием их совмещения является то, что сомнение направлено на выявление ноэтико-ноэматического содержания (в «Картезианских размышлениях» - содержания cogito и cogitatum, соответственно) сознания трансцендентального еgо, а его преодоление возможно при обнаружении единого местонахождения различных еgо - интерсубъективно делимого мира. Всем этим, однако, еще ничего не сказано о возможности и характере эгологического взаимодействия мыслящих субъектов.

Ж.-П. Сартра также занимала проблема соотношения между интенциональным сознанием и моральной самоидентификации еgо cogito. Именно последняя лежит в основе его интерпретации метода Декарта и авторского обоснования теории интерсубъективности. 
Сартр обращает внимание на то, что истолкование Декартом методического сомнения сопряжено с понятием свободной воли и имеет двойственное значение. Исходно акт сомнения служит познанию истины и потому еgо способно свободно отрицать все, что не является истинным ибо «недопустимо, чтобы ложь или несовершенство как таковые проистекали от Бога и чтобы истина или совершенство происходили от небытия» [3, с. 272]. Так, человек сомневается постольку, поскольку это есть путь к засвидетельствованию данного Богом несомненного знания, которое открывается его разуму, благодаря применению метода. В то же время, сомнение является констатацией несовершенства познающего разума, способного к заблуждению в результате неверного устремления воли (ее желания познать больше, чем разум способен постичь). Однако, возможна и иная точка зрения на роль человеческой воли. Сартр подчеркивает, что она утверждает созданные волей Бога истины, которые являются таковыми только посредством свободного соучастия человека в их сотворении. Пояснение этой функции требует отрешения от гносеологической установки эго и обращения к онтологическим основаниям ego cogito.

Его характеристику Декарт предваряет следующим онтологическим допущением, эксплицируемым Сартром: Я может совершать акт негации в силу своего существования иным образом, нежели то, что подвергается отрицанию. Этот аспект картезианского сомнения связан с направленностью рефлексии не на внешнее сущее, а на существование субъекта сомнения: того, кто существует сомневаясъ. В таком случае, не мышление как таковое, но именно акт сомнения, по факту его реализации, является свидетельством собственного существования, которое отлично от существования мира.

Следует отличать сомнение от рефлексии как таковой: выражая определенное содержание рефлексивного акта, сомнение является отрицающим суждением. Следовательно, прежде реализации сомнения, Я должно обладать способностью совершать отрицательное действие, рефлектируя. Так, операция отрицания, согласно Сартру, может быть произведена в виду особого онтологического статуса Я: «Сомнение это разрыв контакта с бытием» [7, с. 24]. По одну сторону этого «разрыва» оказывается мыслящее Я, фиксирующее в акте сомнения отличие собственной природы от всего, что может сделаться предметом сомнения, а по другую - бытие мира: сущее и имеющее интенциональную направленность сознание мыслящего субъекта.

При операции сомнения значение имеет отнюдь не тревога по поводу того, что действительный мир вдруг может оказаться всего лишь 
кажимостью, но противопоставление целокупности сущего, данного в пассивном сознании, субъекту сомнения, способного помыслить, что мира может и не быть.

Когда я спрашиваю: «Есть ли образ действия, который мог бы раскрыть мне отношение человека к миру?» - я в приниипе допускаю возможность отрицательного ответа, как, например: «Нет, такого образа действия не существует». Это означает, что мы соглашаемся поставить себя перед лицом трансцендентного факта несуществования такого образа действия. [...] Так вот, взгляд, брошенный на само вопрошание [...], открывает нам: мы окружены ничто. Именно постоянная возможность небытия вне нас и в нас обусловливает наши вопросы о бытии [6, с. 43-44].

Речь идет о небытии как онтологическом фундаменте Я, которое не существует подобно вещам мира. Мир сущего может быть постигнут в целостности своего существования только потому, что некто, кто сам не существуя тем же образом, заявляет о себе в вопросе о природе существования, как такового. Проблема состоит не в том, существует ли сущее, воспринимаемое в фактическом опыте, но в том, как в принципе возможно знание о существовании мира. Согласно Сартру, оно не может быть постигнуто изнутри мира, а является точкой зрения субъекта, трансцендентного бытию мира ${ }^{3}$.

Критикуя гуссерлианский подход к интерпретации метода Декарта, Сартр не принимает предложенное Гусселем различение «пустого» сознания и коррелятивного ему трансцендентного мира. Сознание есть всегда сознание чего-то, не познающее свой предмет, а констатирующее его бытие. Сознание черпает все свое содержание из мира, бытие которого, поэтому, не просто не может быть подвержено сомнению, но впервые открывается именно как бытийствующее в сознающем его сознании:

Сознание есть бытие, существование которого полагает сущность, и наоборот, оно есть сознание бытия, сущность которого подразумевает существование, то есть видимость которого требует бытия [6, с. 35].

Редуцирование мира является особой гносеологической процедурой, которая не должна иметь своим последствием сомнение в его

\footnotetext{
${ }^{3}$ Интерпретация Сартром негативности формировалась под влиянием текстов А. Кожева и ранних работ М. Хайдеггера. В контексте экзистенциальной проблематики картезианское сомнение в том «существует ли» мир скрещивается с хайдеггерианским «почему вообще есть сущее, а не, наоборот, Ничто?» («Что такое метафизика?»), спрошенное перед лицом Другого. Проблема теперь заключается в том, существует ли мир $\operatorname{ma\kappa }$, как известно об этом мне, ибо, кроме этого знания о мире, я знаю Другого с его инъм восприятием и суждением о мире.
} 
существовании. Неуверенность по поводу достоверности конкретных эмпирических данных (было ли нечто иллюзией или имело место в действительности) предполагает исходное наличие опыта реальности, потому сомнение в существовании мира, порождающее солипсистскую установку, излишне. Мир определенно существует, а феноменологическая установка, занимаемая по проведении редукции, лишь уберегает феноменолога от поспешных суждений о том, существует ли конкретная данность опыта: мир в такой или иной явленности сознанию ${ }^{4}$. Ошибка Гуссерля заключается в том, что исследуя сознание, он элиминировал бытие предмета сознания и, тем самым, рассматривал сознание в единстве с мыслящим $Я$, а не с интенционально фиксируемыми данностями. Восприятие действительности в ее существовании предполагает определенную структуру бытия, а именно, взаимное полагание «в-себе» сущего и «для-себя» интенционального, «прозрачного» сознания. Сартр пишет:

Нет никакого примата рефлексии вместе с отражающим сознанием: ведь не это позволяет ему открыть самого себя. Совсем наоборот, именно нерефлексивное сознание делает рефлексию возможной. Есть дорефлексивное cogito, которое и составляет условие картезианского cogito [6, с. 27].

Интуитивное и дорефлексивное схватывание сознанием действительности, свидетельствующее о бытии сущего отраженного в сознании, Сартр противопоставляет рефлексии, функция которой, напротив, лежит в негации предметов, которые оказываются за пределами ее направленности ${ }^{5}$. Такое отрицание связано не с сомнением в их существовании, а с конкретным смыслом (например, «встретить Пьера»), который определяет действительность как актуальную (лицо Пьера) или не актуальную (кафе, как фон) для всматривания. В конечном счете, такая погоня за смыслом объясняется присущим Я желанием обрести собственную завершенность или целостность. Вопреки недостижимости последней, она выступает в качестве подлинного горизонта, на который ориентировано Я, будучи в естестве своем не-субстан-

\footnotetext{
${ }^{4}$ Солипсизм понят Гуссерлем не как методический шаг, но как характеристика примордиальной сферы сознания, онтологически первичной относительно всего, что ей внеположено. См.: Гуцалов А.А. Эволюция проблемы интерсубъективности в феноменологии Эдмунда Гуссерля от воображения к пассивному синтезу // Вестник РГГУ. - 2008. - № 7. - С. 37-50.

5 Это положение иллюстрирует приводимый Сартром пример с Пьером, ожидание увидеть в кафе которого превращает кафе в фон, существование которого остается актуально невоспринятым в сознании того, чье внимание захвачено ожиданием увидеть в обстановке конкретное лицо (см.: [6, глава $1, \S 2])$.
} 
циональным и вневременным. Так, акт познания, в строгом смысле, есть дело мыслящего субъекта, а не сознания, пассивно воспринимающего предмет своей направленности и онтологически единого с ним.

Отталкиваясь при построении концепции интерсубъективности от разделения между сознанием и бытием объективного мира, Гуссерль представляет дело так, будто Я мыслящее конституирует в поле своего сознания другого субъекта, который удостоверяя действительное существование мира, предполагает вместе с тем и существование самого этого Я, взятое уже не как трансцендентальное, но как трансцендентное. Такая двойственность установки, в которой ведутся поиски Другого, устраняется следующим требованием Сартра:

Давайте же будем более радикальными и смело заявим, что посредством єлоқ̆́ должна быть отсечена всякая трансцендентность; [...] Так как Я в [акте] «Я мыслю» утверждает само себя как трансцендентное, оно имеет природу, отличающуюся от природы трансцендентального сознания [8, с. 95].

Он противопоставляет феноменальный пласт сознания персонализирующему его центру, выступающему как предмет интенционального схватывания первого, подобно вещам мира.

Сартр указывает на то, что «Гуссерль сохранил трансцендентальный субъект, который здесь совершенно отчетлив и сильно похож на кантовский субъект» $[6$, с. 258] первой «Критики», признавая их обоюдную несостоятельность на пути познания Другого. Однако, как уже было сказано, в отличие от Гуссерля, Кант не претендовал на решение этой проблемы путем дескрипции структуры сознания. Сопоставляя системы Канта и Сартра, последнего можно считать продолжателем традиции, идущей от «Критики практического разума». Новшество сартровской позиции состоит в том, что фундаментом нравственного действия является не скрепленное высшим авторитетом обязательство (подобно свободному исполнению долга перед Богом, являющимся причиной абсолютности категорического императива), но абсолютная свобода к самоосуществлению. Бог не только не полагает существование еgо в свободе, но свобода, понятая как основание онтологии субъекта, делает излишними любые теологические построения.

Элиминируя еgо из гуссерлианской конструкции, Сартр замещает его тем, что лежит в основе эгологического самоосознания, раскалывая мыслящего субъекта на возможности, выбирая из которых, он образовывает себя самое: «ничто заключено в недрах трансцендентности [ego] и обуславливает ее» [6, с. 56], будучи онтологическим основанием свободно существующего Я. 
Отталкиваясь от данной интерпретации свободы, Сартр излагает собственное видение природы интерсубъективности. Так, он пишет:

Человек, постигающий себя через cogito, непосредственно обнаруживает вместе с тем и всех других, и притом - как условие своего собственного существования. [...] обнаружение моего внутреннего мира открывает мне в то же время и другого, как стоящую передо мной свободу, которая мыслит и желает «за» или «против» меня. Таким образом, открывается целый мир, который мы называем интерсубъективностью [9, с. 95].

Имеет принципиальное значение обстоятельство, что такая взаимосвязь с Другим не может быть раскрыта исходя из дескрипции процессов, протекающих в сознании и имеющих темпоральную основу, но осуществляются в царстве смысла. Сартр пишет:

Безусловно также, что значение «другой» не может прийти ни из опыта, ни из рассуждения по аналогии проведенного по случаю опыта; напротив, именно в свете понятия другого интерпретируется опыт. [...] Таким образом, подлинной проблемой [интерсубъективности] является проблема связи трансцендентальных субъектов по ту сторону опыта $[6$, с. 258$]$.

По поводу мысли Гуссерля, согласно которой Другой является одним из тех, кто конституирует сообща один и тот же мир, признаваемый на основании этого существующим, Сартр замечает:

Гуссерль отвечает солипсисту, что существование другого так же достоверно, как существование мира; но солипсист и не говорит другой вещи; существование мира так же достоверно, скажет он, но не больше [там же, с. 259].

Более того, парадоксальность концепции Гуссерля в том, что путем нахождения alter ego таким образом, солипсизм отнюдь не преодолевается, так как каждая монада остается замкнутой в пределах горизонта собственного опыта. Имеется, скорее, множественность отъединенных универсумов, центром каждого из которых является монадическое еgo $^{6}$. Следовательно, преодоление солипсизма предполагает иную установку обретения Другого, а соответственно, и иное место, с позиций которого совершается констатация существования одного и того же мира.

Мое отношение с другим является с самого начала и существенно отношением бытия с бытием, а не познания с познанием, если солипсизм должен и может быть опровергнут [6, с. 267].

\footnotetext{
${ }^{6}$ Подробнее об этом см.: [5, с. 36$]$.
} 
Сартр противопоставляет субъекта, который обретает собственное бытие перед лицом Другого, трансцендентного подобно ему самому, гуссерлианской версии аппрезентации Другого, конституируемого внутри мира. Согласно Сартру, он находится по ту сторону горизонта интенционального опыта: «Другого встречают, его не конституируют» [там же, с. 273]. Поскольку же трансцендентальному еgо ничего неизвестно о собственном существовании, его ориентация на чужое еgо, в действительности, носит познавательный характер, и потому ее результаты не могут считаться аподиктическими.

Еще одно фундаментальное различие между подходом Гуссерля и Сартра в описании межсубъектной взаимоположенности состоит в том, что, согласно первому, сначала происходит конституирование тела Другого и лишь затем, по аналогии с взаимосвязанностью собственного Я и тела, возможно схватывание в чужом теле еgо, подобное моему. Сартр же метко замечает, что тело Другого является не тем, что объединяет двух Я в едином мире, но оно, напротив, оказывается преградой для их абсолютного взаимодействия. Это, опять таки, связано с тем, что существование Я онтологически отлично от существования принадлежащего миру тела:

Другой присутствует во мне без всякого посредника как трансцендентность, которая не является моей. Но это присутствие не взаимно; необходима вся толщина мира, чтобы я присутствовал по отношению к другому [там же, с. 292].

В свою очередь, взгляд Другого, направленный на Я, как бы извлекает его из мира наличных предметов, выступая ядром, по направлению к которому «мир течет за свои пределы, и я вытекаю из себя» [там же, c. 280].

Стоит отметить, что Другой удостоверяет и оправдывает акт вопрошания субъекта о существовании мира и его самого в том же смысле, в котором картезианский Бог гарантировал истинный ответ на такой вопрос. Осмысляя естество последнего, Сартр обращает внимание на то, что его совершенство - не единственная характеристика, которая помогает понять границы, в которых применение методического сомнения правомерно. Рационально постигая устройство сотворенного Богом мира, мы имеем дело с плодом его деятельности ${ }^{7}$, но не с его

\footnotetext{
${ }^{7}$ См. высказывание Декарта, которое приводит Сартр: «В отношении вечных истин я вновь утверждаю, что положения эти истинны или возможны лишь потому, что Бог знает их как истинные или возможные, а отнюдь не наоборот - будто они ведомы Богу как истинные, будучи истинными независимо от него» (цит. по: [7, c. 26]).
} 
свободной волей. Сартр пишет:

Божественная свобода [...] это чистая продуктивность, вневременной и вечный акт, посредством которого Бог творит мир, Благо и вечные Истины. Поэтому корень всякого Разума следует искать в природе свободного акта; именно свобода лежит в основании истины $[7, \text { с. } 26]^{8}$.

Так, следуя мысли Сартра, мы должны решиться на перестановку фундаментальных понятий картезианской концепции: свобода предшествует интеллектуально постигаемым истинам и сама есть подлинное основание совершенства.

Характерно, что истина познавательной деятельности может быть засвидетельствована именно рефлексивно, идет ли речь об идеях, интенционально воспринимаемых в сознании или познания себя, как отраженной в другом свободы: «Только рефлексивное сознание имеет объектом я непосредственно» [6, с. 283]. И далее: «я его [эго] постигаю, как оно не является для меня, и поскольку оно в принципе существует для другого» [там же, с. 284]. Равно и для Другого «мое бытие-объекта [...] есть очевидность того же самого типа, что и рефлексивная очевидность» [там же, с. 302]. Объективация существования Я возможна посредством его признания другим еgо и, наоборот, Я само способно объективировать Другого, выступая в качестве трансцендентного ему субъекта. Так, Другой является гарантом, превращающим возможности конкретного Я в зафиксированную им действительность того, чем это Я есть, предваряя и трансформируя его самоданность в свободе и собственном мире.

Согласно Сартру,

между другим и мною есть ничто разделения. Это ничто не образуется ни из меня, ни из другого, ни из взаимного отношения другого и меня; оно, напротив, первоначально есть основа всякого отношения между другим и мною как первичное отсутствие отношения [6, с. 254].

Такое отсутствие отсылает к поиску Другого не вовне мира, где оно реализовано, но, напротив, в глубине нас самих.

${ }^{8} \mathrm{~B}$ несколько ином контексте указывает на особенность картезианской интерпретации свободы Бога Э. Жильсон. В отличие от предшествующей Декарту схоластической традиции, различающей в Боге оперирующий неизменными истинами разум и творящую, согласно его законам, волю, Декарт считал свободный акт творения как истоком полагания сущностей, истин разума, так и их реального воплощения в мире. См. подробнее: Жильсон Э. Учение Декарта о свободе и теология // Жильсон Э. Избранное. Христианская философия. - М. : Книга света, 2004. C. 5-320. 
Если речь идет о том, чтобы попытаться сделать, так сказать, для другого то, что пытался сделать Декарт для Бога этим необычным «доказательством посредством идеи совершенного», которая полностью вдохновлена интуицией трансцендентного, то [...] Другой должен появиться в Cogito как не являющийся мною [там же, с. 275].

Следовательно, Другой не должен быть причастным моему миру, конституируемому в сознании. Потому «множество "других" не может быть набором ${ }^{9}$, но целостностью» [там же, с. 275], характеризующейся не темпоральными процессами в трансцендентальном поле каждого из субъектов, но идеальностью их общего, трансцендентного основания.

Другой «заставляет меня быть по ту сторону моего бытия в этом мире» [там же, с. 280], тем самым восстанавливая единство меня с самим собой как бы извне всей широты мира, конституируемого в сознании. Другой, указывает Сартр, не есть тот, с кем Я может «знать совместно» один и тот же мир, что следует из феноменологии Гуссерля или даже «делать совместно» в мире, в смысле хайдеггеровского «mitmachen». Напротив, Другой и Я изначально существуют как единство, расчленяемое фактичностью своего положения по отношению друг к другу: «бытие-для-другого может быть, только если оно является бывшим через целостность, которая теряется, чтобы оно возникло» [там же, с. 322].

На этой почве, Другой, утратив картезианский ореол божественности, тем не менее, подобно ему, постигается в самой сердцевине Я. Именно он, а не недостоверность эмпирических данных, является условием и причиной постановки вопроса о существовании мира. Так, методическое сомнение Декарта, с позиции сартровской феноменологоонтологической интерпретации, не только не ведет к солипсизму, но должно быть понято исключительно как следствие глубинного интерсубъективного единства мыслящих Я.

\section{Литература}

[1] Гуссерль Э. Картезианские размышления. - СПб. : Наука, 2006.

[2] Декарт Р. Размышления о первой философии // Декарт Р. Сочинения в двух томах. - М. : Мысль, 1994. - Т. 2.

\footnotetext{
${ }^{9}$ Подобно гуссерлианскому сообществу монад, существующих в едином мире.
} 
[3] Декарт Р. Рассуждения о методе // Декарт Р. Сочинения в двух томах. - М. : Мысль, 1994. - Т. 1.

[4] Кэлер K. Сознание и его феномены: Лейбниц, Кант и Гуссерль / HORIZON. Феноменологические исследования. - 2014. - № 3 (1). - C. 169-190.

[5] Литвиновская М.Л. Истоки теории монадического сообщества Э. Гуссерля / Известия РГПУ им. А.И. Герцена. - 2009. - № 89. - C. 31-38.

[6] Сартр Ж.-П. Бытие и ничто: Опыт феноменологической онтологии. - М. : Республика, 2000.

[7] Сартр Ж.-П. Картезианская свобода // Логос. - 1996. - № 8. c. $17-32$.

[8] Сартр Ж.-П. Трансцендентность Эго. Набросок феноменологического описания // Логос. - 2003. - № 2 (37). - С. 86-121

[9] Сартр ЖК.-П. Экзистенциализм - это гуманизм // Сумерки богов. - М. : Политиздат, 1990. - С. 319-344.

Надійшла до редакиї 2 березня 2015 р. 